\title{
ARTIFICIAL INTELLIGENCE IN HEALTHCARE: 21ST CENTURY AGE OF RIFLES - A BIBLIOMETRIC ANALYSIS
}

\author{
R K Premal*, M Kathiravan², Asmat Ara Shaikh³ \\ 1. Acharya Bangalore B School, Bangalore, India \\ 2. The Oxford College of Engineering, Bangalore, Karnataka, India \\ 3. Bharati Vidyapeeth's Institute of Management Studies and Research, Navi Mumbai, India
}

Correspondence: rprema86@gmail.com

\begin{abstract}
In the 21 st century data, itself are information, product, and goods. The pandemic situation has given new eyes to the old invention to effectively bridge the gap between history, happenings, and technology as well as past and future. Health is requisite and every one of us would have placed our footstep one way or the another in the healthcare sector. The demand for healthcare professionals is also increasing in our country with an increasing population. To address the health need of society, this paper attempts to exhibit the studies captured on these two broad areas in the healthcare sector with a systematic literature review of bibliometric analysis. This paper will bring out the technological invention, its implications in the 21 st century, relevance in the covid 19 pandemic situation, research, and facts explored in this area. Humans are the inventor and users of technology: the good we use the great will be the outcome: It all depends.
\end{abstract}

\section{KEYWORDS}

Artificial Intelligence, Technology, Bibliometric, Pandemic

\section{BACKGROUND \& INTRODUCTION}

The 21 st-century healthcare market is facing more or less unique challenges globally. Even the most advanced countries struggle to fit with the proper infrastructure to integrate diverse job functions in delivering quality care. India has a diverse population of $139 \mathrm{cr}$ people rank second among one-third of the world population as per Worldometers statistics. Worldometers is the free reference website by the American Library Association (ALA), the oldest and largest library association in the world.
Healthcare is one of the dynamic and challenging sectors, due to the following reasons: 1. Increasing population 2.24/7 service in the customer-centric business 3 . Better Care: Shortage of health professionals and quality care: 4 . Unstructured Medical Data 5. Accessibility of healthcare across India. There is a dire need for Al systems and public health interventions in the pandemic situation and future. [1] Addressing these concerns through the 21st century "Age of Rifle" is the "Artificial Intelligence." Rifle is a gun, used in war to win enemies. The authors justify "Al as the $21^{\text {st }}$ 
century age of rifles" which could win the challenges in healthcare. Al solutions in healthcare can augment these scarce resources and will scale it up. If applied in healthcare, Al has the tremendous potential to improve by leaps and bounds and better-quality care. To address the health need of society, Artificial Intelligence serves far better not only in reducing the mundane task but very accurate in medical imaging, preliminary diagnosis, discovering new medicines, Al-assisted surgeries, and virtual nursing assistants. This paper attempt to exhibit the studies captured on the broad areas in the healthcare sector with a systematic literature review of bibliometric analysis.

\section{ARTIFICIAL INTELLIGENCES IN INDIAN HEALTH CARE}

The World Health Organization stresses Universal health coverage to the population. Policy advice reports that the global healthcare spending expects to reach 10 trillion dollars by 2022, whereas the Indian hospital industry expects to increase to Rs. 8.6 trillion 132.84 billion dollars by 2022 at a compound annual growth rate of $16-17 \%$ as depicted by IBEF. Concerning this report, healthcare is topnotch, and to address the challenges and fulfill the irequirements Al will be a great solution. [2]

$\mathrm{Al}$ is creating and will create an evolutionary world in the global healthcare system. Al expects to bring the possible outcome to the existing problems due to its limitless ability. In the last ten years, there has been vast extensive growth in the scientific literature field of $\mathrm{Al}$ in healthcare. Technology adoption is the robust challenge for all sectors. [3] The digital era sprouted the IT field for the Al systems to gear up so fast and vast; instead, it is not new. History says even in Aristotle syllogism in $300 \mathrm{BC}$ [4], the concept of $\mathrm{Al}$ existed, traced way back to philosophy, fiction, and imagination [5], but not so clear and concrete.

\section{MATERIALS AND METHODS}

Bibliometric analysis is the evaluation of published scientific articles. [6] justifies and recommends bibliometric analysis as the most preferred tool for literature review. The idea of bibliometric analysis primarily studies the results of extant research on a specified area, including the most addressed theme or trends related to the topic. [7] It also depends on the study on the sample, the country, and the methodology used, etc. [8] The study design follows research objective, research design, bibliometric data curtain, methodology and software used, analysis and results, interpretations and findings, and conclusion with future implications in the following sections.

\section{SEARCH STRATEGY}

We search the research papers from the "DIMENSION Database" systematically using the most relevant key search terms such as Artificial Intelligence, Healthcare, Covid 19 Boolean search terms such as Artificial Intelligence AND Healthcare, Artificial Intelligence, AND Implementation.

\section{FIGURE 1: OVERVIEW OF DOCUMENTS CITATION FROM THE DATABASE}
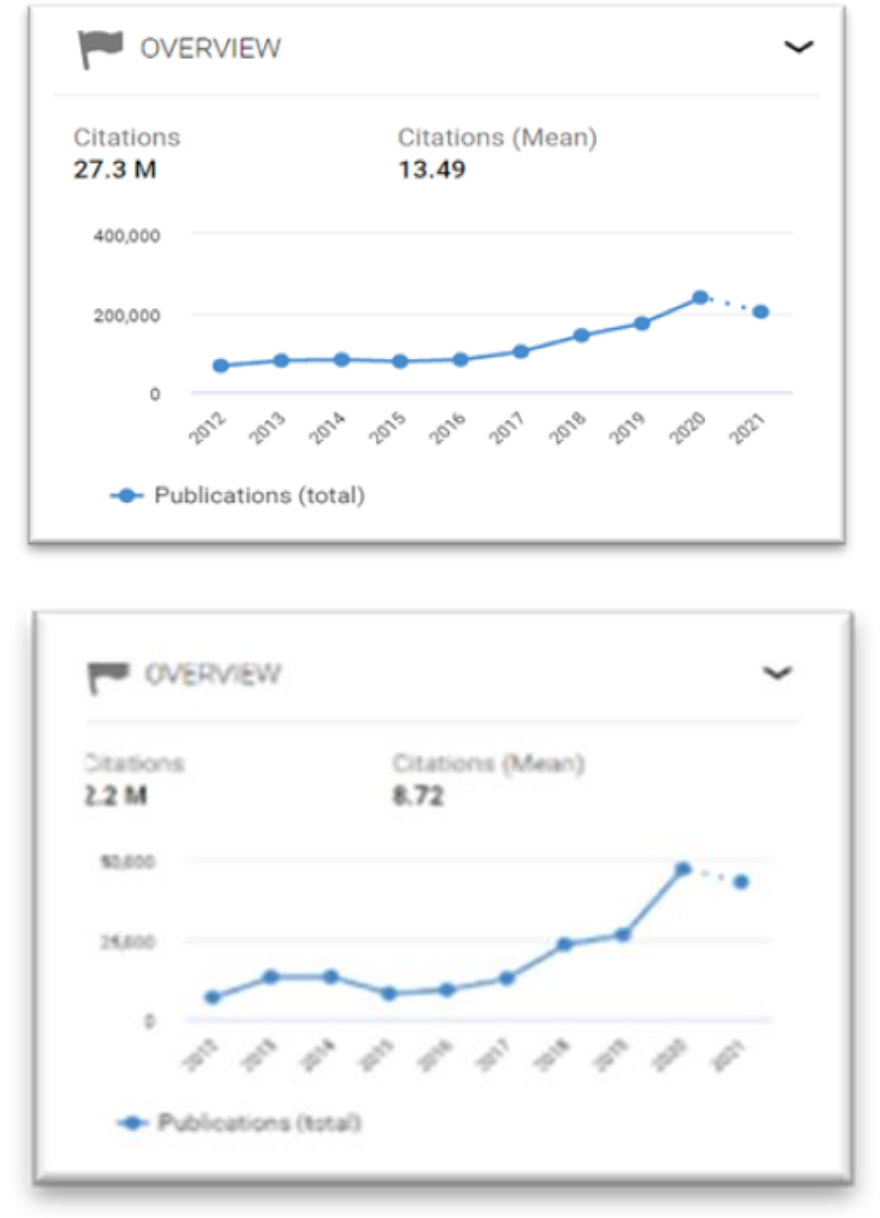

Source: DIMENSIONS Database

When the researcher hit the term Artificial Intelligence, across all the areas is $27.3 \mathrm{M}$ with an average citation of 13.49. Figure 1: For the critical term Artificial Intelligence AND Healthcare, the study hits found around 2.2M with an average citation of 8.72 of the paper stored in Dimension database. The database has documents related to the search from the year 1900 to 2021 . With the number of 
articles 1 to 43,108, the highest number of publications is in 2020, and the range increases from 2017 onwards.

\section{SCREENING STRATEGY}

The search strategy used for the study is depicted in the form of PRISMA flow diagram.

FIGURE 2: PRISMA FLOW DIAGRAM

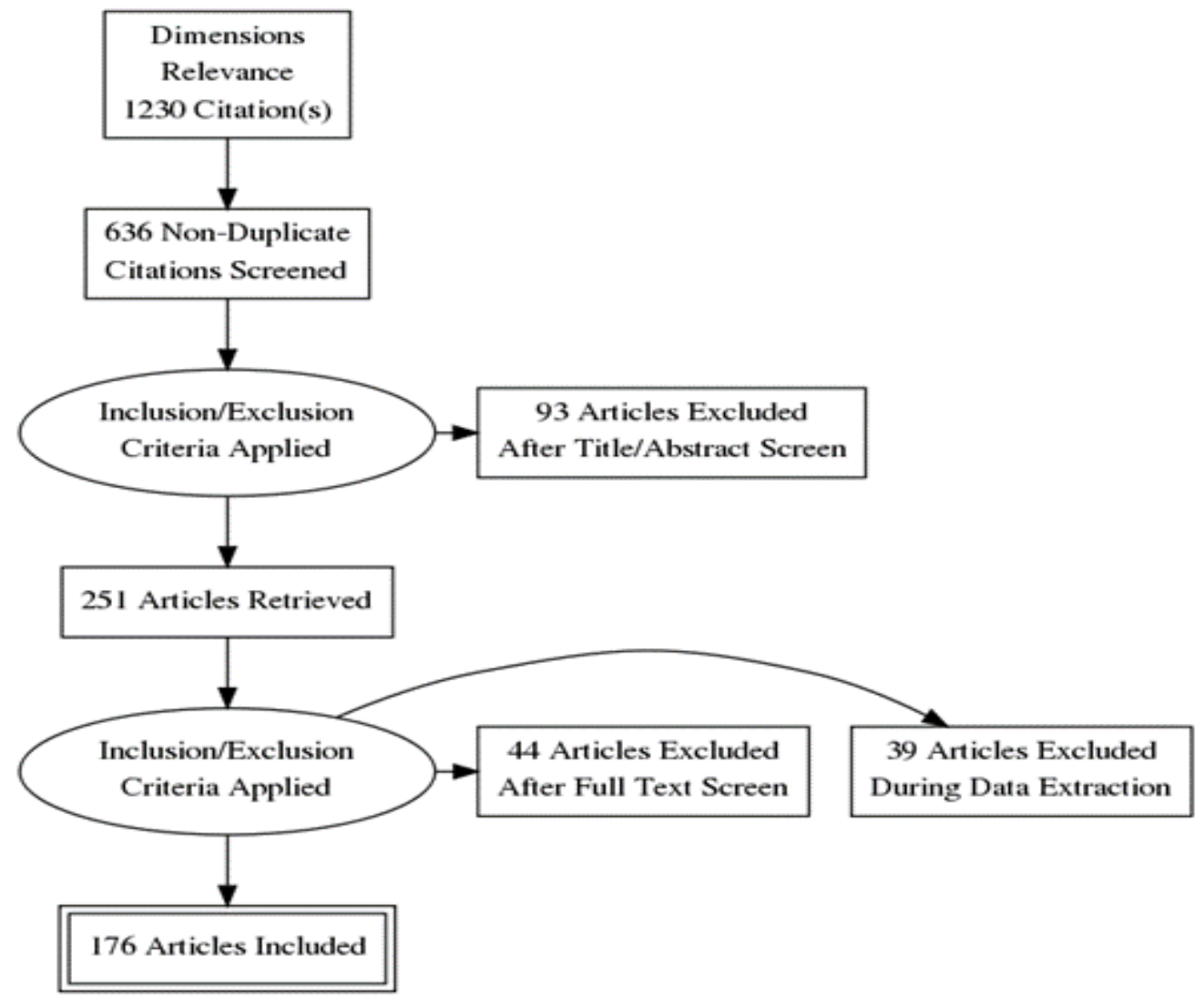

Source: Authors' own

\section{SOFTWARE AND DATA ANALYSIS}

The bibliometric analysis presented in the document is derived with the help of Vos viewer [9] and MS-Excel. With the help of indicators such as co-occurrences of keywords, trend topics in the area, most productive countries, citation network, authors coupling, country collaboration, the researchers developed a graphical mapping of the bibliographic material. Finally, 166 papers were identified

as the input file for the VOS viewer for further extraction of results. The output of the analysis done with its figures and interpretations using MS-Excel are discussed hereunder.

\section{RESULTS AND DISCUSSION}

\section{PUBLICATION PATTERN}

The number of publications in the domain carries a good trend. The papers published in the year 2020 possess a greater citation compared to the consequent years. It is also observed that as per the papers collected from the database, there is a slight dip in the number of documents done in the year 2021. This may be because the focus is shifting towards machine learning, deep learning concepts, and advanced technologies.

\section{COUNTRIES BIBLIOGRAPHIC COUPLING}

The bibliometric coupling among the countries exhibits that the United States has the highest strength with (TLS: 2265), Australia (TLS:1632), and Canada (TLS:1309). The majority of the $\mathrm{Al}$ research occurs in collaboration with the United States, with 18 clusters 1. The coupling has 3 clusters, wherein India comes under cluster 2, collaborating with Canada, Japan, Sweden, China, and United Arab Emirates.[10] states that Canada will quickly be a leader in Al. The above visualization aligns with the discussion of [1 1] that the United States has the most active researching country in Al. 
FIG 3: PUBLICATION PATTERN OVERTIME ON ARTIFICIAL INTELLIGENCE IN HEALTHCARE (SOURCE- AUTHORS' OWN)

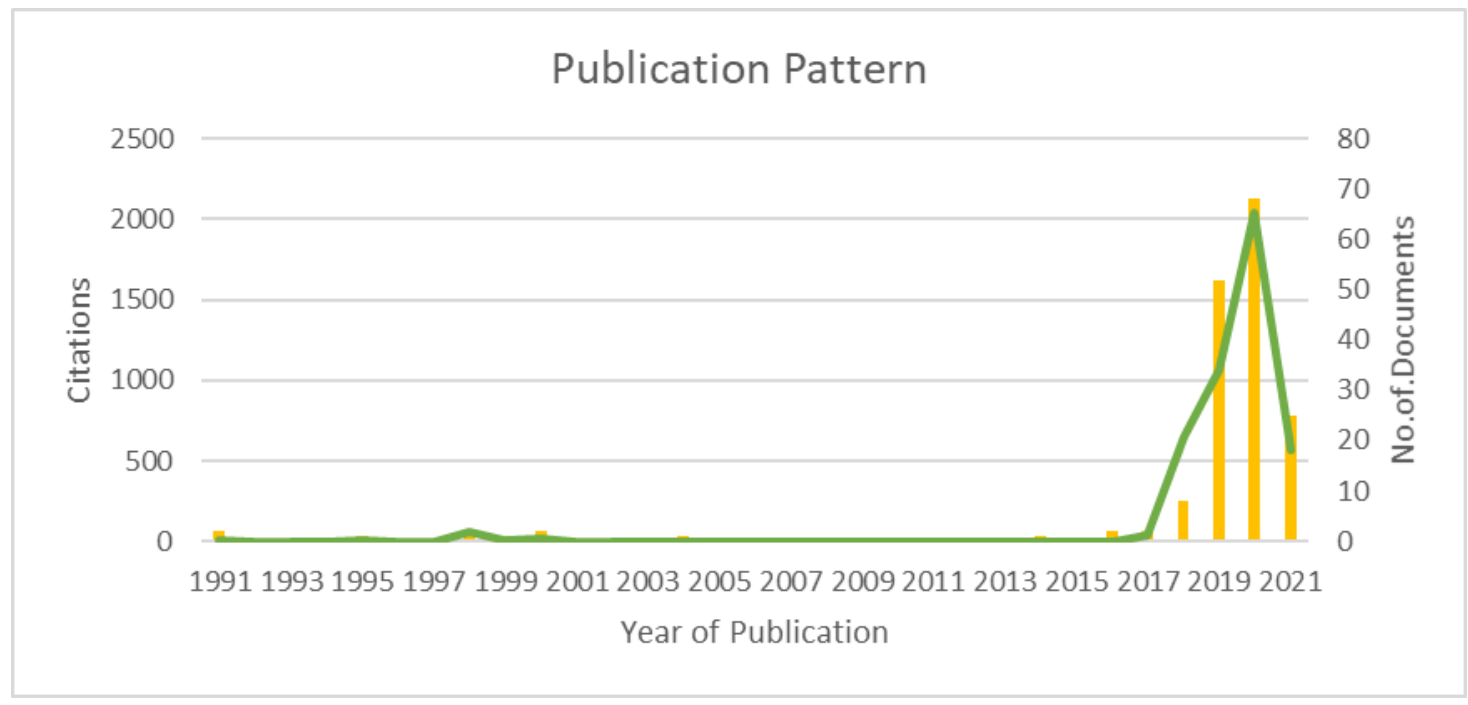

FIG 4: BIBLIOGRAPHIC COUPLING OF COUNTRIES (SOURCE- AUTHORS' OWN)

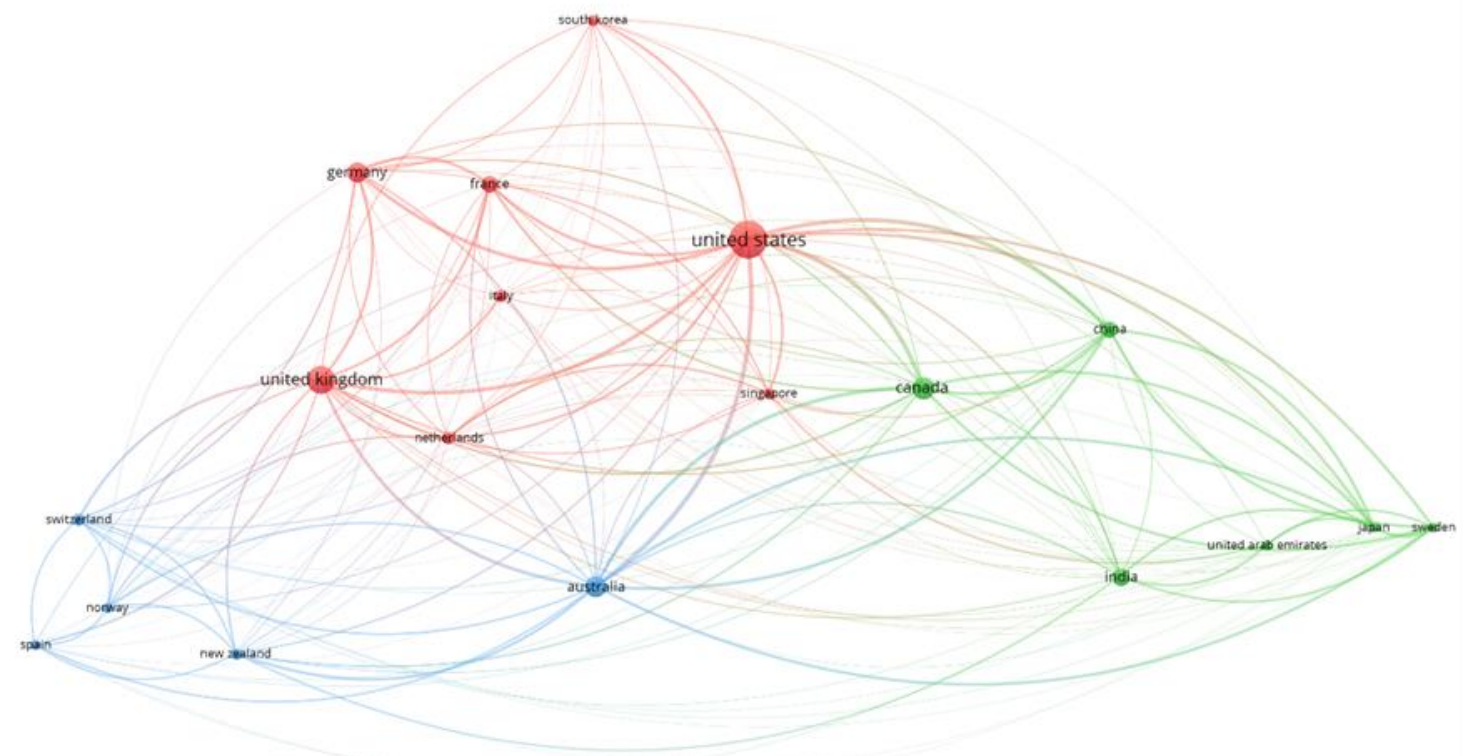

A vosviewer

FIGURE 5: COUNTRIES PUBLICATION

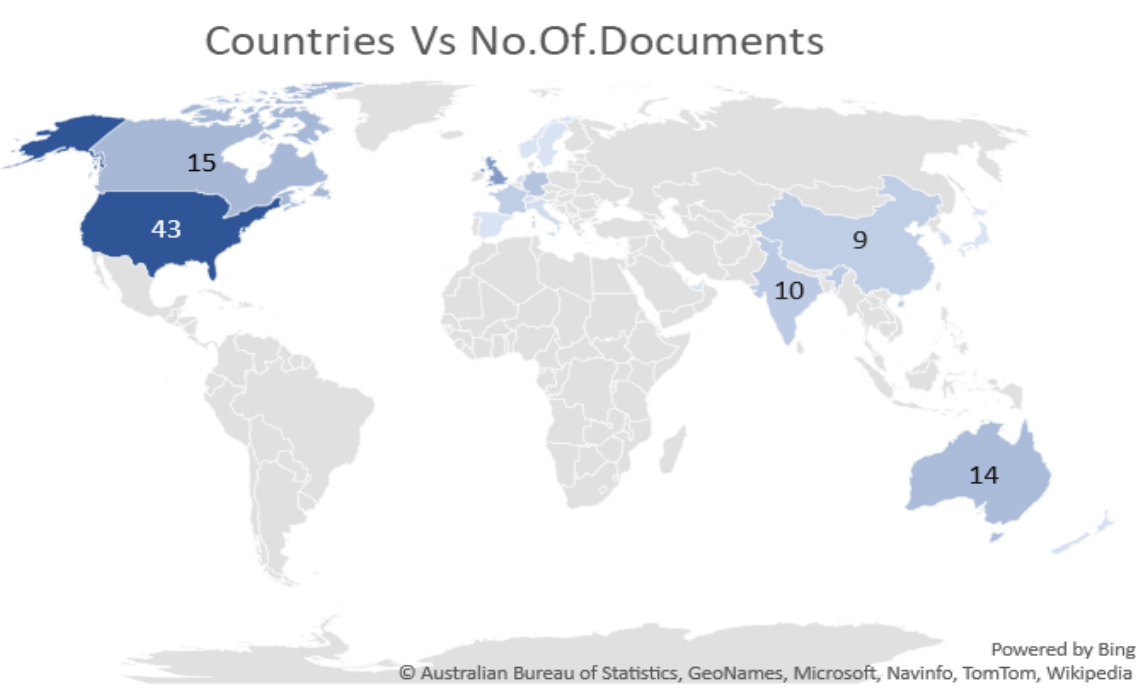




\section{CO-CITATION DENSITY PLOT}

The density Plot of Co-citation of cited authors in the database is presented here. The output delivered 5 clusters with a maximum threshold of 12 citations. A total of 83 documents were identified with the authors peng, lily having a maximum Total link strength of 1100 with 33 as the higher citation derived. For the clusters identified density visualization chart is presented

The authors tried to explore the relationship of coauthorship of authors and countries. The table presented here projects the seven top co-authorship as the type of analysis and the unit of analysis as authors, separate analysis with countries is done. For the co-authorship of authors, we apply a threshold value of $2: 2$. For coauthorship of countries, we apply a threshold of 3:2. It is observed that the authors Javid, Mohd is in the first rank with a citation of 608 among the co-authorship. The top 7 countries with their citations and the total link strength are given. In the co-authorship relationship with countries, India holds rank 3 with a total link strength of 8 . There is a greater need for the researcher to work collaboratively in the domain of $\mathrm{Al}$ in healthcare.

\section{DOCUMENTS CITATION}

Citation as the type of analysis and documents unit of analysis with a maximum threshold of a minimum number of citations of a paper, ten is fixed. The output overlay visualization of the Vos viewer is shown hereunder. Thirtyone documents are identified and presented under two clusters in the network visualization and spread among three years in the overlay visualization from 2018 to 2021.

\section{FIGURE 6: DENSITY PLOT FOR THE IDENTIFIED CLUSTERS FOR CO-CITATION OF THE CITED AUTHORS.}

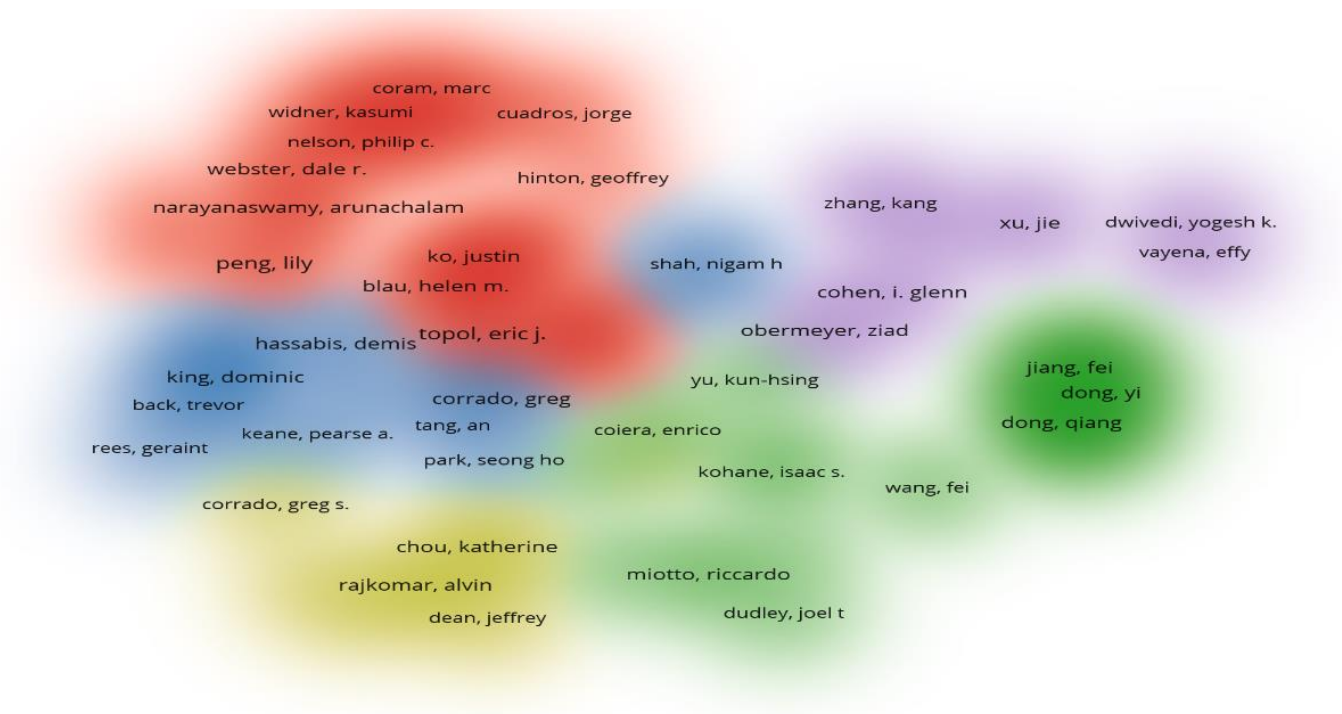

\& Vosviewer

Source: Authors' own Co-authorship of authors \& co-authorship of countries

TABLE 1: CO-AUTHORSHIP OF AUTHORS \& CO-AUTHORSHIP OF COUNTRIES

\begin{tabular}{lllllll} 
S.NO & Author & Citations & S.NO & Country & Citation & TLS \\
\hline 1 & javaid, mohd & 608 & 1 & United states & 1223 & 16 \\
2 & vaishya, raju & 608 & 2 & $\begin{array}{l}\text { United } \\
\text { kingdom }\end{array}$ & 865 & 18 \\
3 & haleem, abid & 608 & 3 & India & 698 & 8 \\
4 & reddy, Sandeep & 132 & 4 & China & 510 & 9 \\
5 & meskó, bertalan & 99 & 5 & Australia & 280 & 19 \\
6 & kuziemsky, craig & 62 & 6 & Canada & 217 & 11 \\
7 & coghlan, simon & 59 & 7 & Singapore & 205 & 4 \\
\hline
\end{tabular}




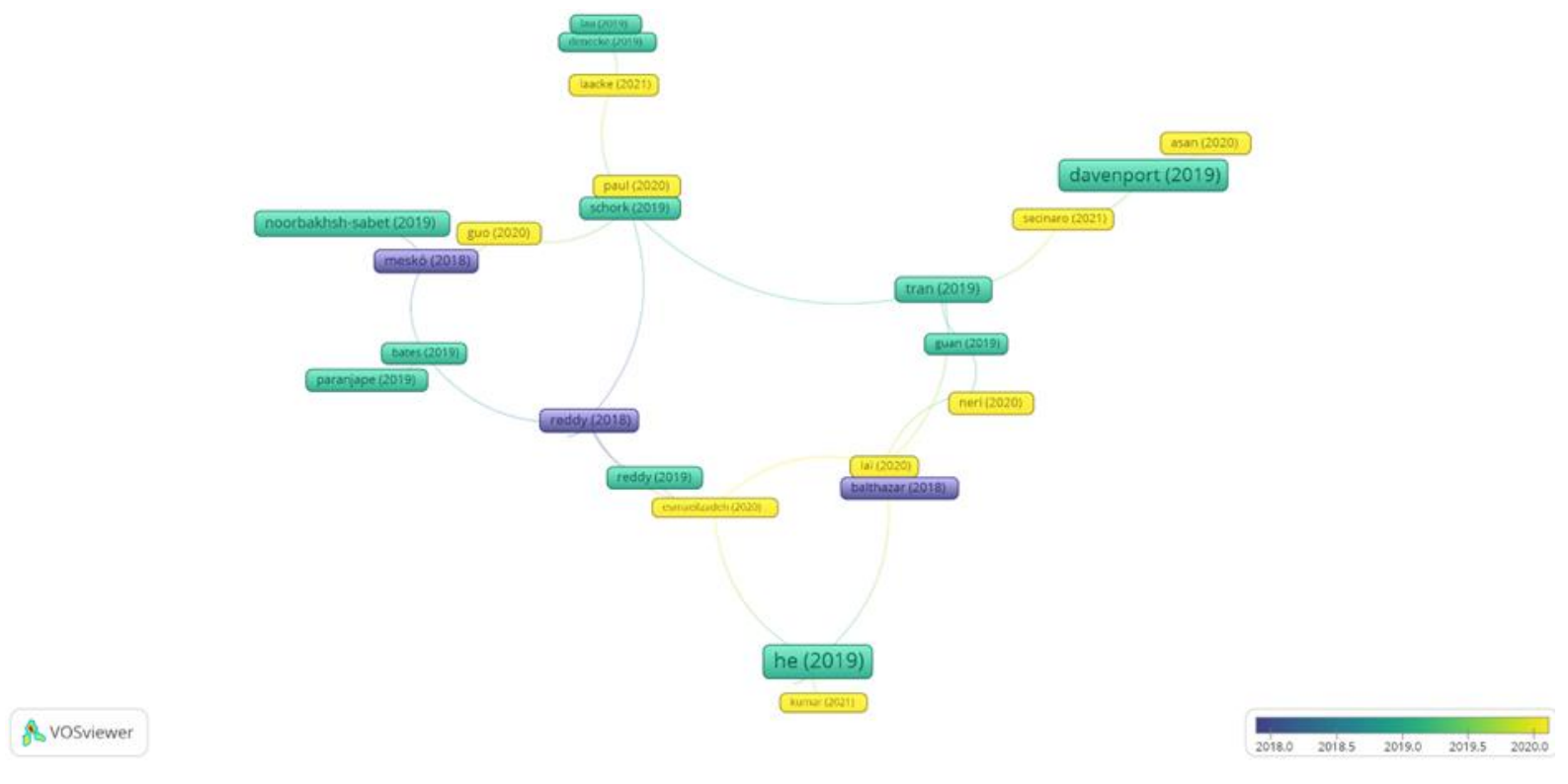

Source: Authors' own

A report by PWC states that the contribution of $\mathrm{Al}$ will be an addition of 15.7 dollars trillion to the world economy by 2030, the most significant impact in healthcare. In terms of policy implications, the study put forth three suggestions. 1. The wide application of $\mathrm{Al}$ is in Pre-diagnosis and maintaining EHR; growth will be for sure. The government can go for an IT-enabled Health care division to build strong foundations in medical research using Al Systems. 2. Developing countries like India can support funds for research to induce the application of $\mathrm{Al}$ in healthcare, and we are lagging behind many countries in the application part. Neighbor country collaboration may help for new inventions and applications in the field of Al systems. In line with [12][13], Al requires integration, multidisciplinary collaboration in the medical workflow process. 3. The service delivery divide between public and private hospitals needs to be considered for the better availability of services to the man living in the corner of the road. It is necessary to formulate global and national protocols for efficient use in and to ensure the growth and solidarity of $\mathrm{Al}$ applications and development in medical. Al systems provide an effective diagnosis quickly, so the future investment is appreciable [14]. Having specific architecture, consciousness of Al systems, and data privacy will be the concern challenges in this field [15].

\section{TOP 10 CITED PAPERS ARGUMENTS ON ARTIFICIAL INTELLIGENCE}

The 21 st-century transformative technology in healthcare is Artificial Intelligence. [16] [17] [18] The complexity in the healthcare delivery lies because of the voluminous data generated during the process, which can address with the help of Al systems reasonably. A hyperbolic effect exists in the domain of $\mathrm{Al}$. It is time to facilitate the arrival of $\mathrm{Al}$ and big data by working together collaboratively to get a concrete stand in the applicability of Al in medicine [19] to reap the benefits. Future research collaborating with the professionals, developers, legislators, and customers to address the explain ability status [20] and tackle the persisting challenges of $\mathrm{Al}$ in healthcare. The initial development stage may cost little, but benefits we can reap in the future. [21] Following that [22], One of the potential markets is healthcare, and extensive use of AI will optimize cost and enhance service quality.

In healthcare, Al is being used widely to increase the efficacy of the healthcare industry. [23] Al has the potential to transform administrative processes and patient care, one great interpretation of [24] study is that Al will not lead to human replacement on a large scale; instead, we can utilize it for better-quality patient care. A review article by Yu et al [25] presents that the clinical integration of medical Al varies at different developmental stages. There are areas like serum analyser where Al system performs reliably 
than a human expert, few levels reasonable, few expert groups like so. The potential benefits of Al systems exist, and also it will not lead to job loss., on the other hand, prepare manpower for a varied job role to work with Al systems. Though Al in healthcare is gaining prominent attention, the implementation phase is rigid to get things out in a broader way; one such is the lack of standards regarding Al systems' efficacy and safety. [26]

\section{CONCLUSIONS}

Ever-increasing will be the demand for the healthcare sector and health professionals are facing hectic challenges. [27] The idea of $\mathrm{Al}$ is to enhance the user experience. The service Industry must predict and be aware of customer expectations. It adds significant value in understanding the customer and their trends. We need to take many steps to fix the gap in the Indian healthcare industry to adopt digital inventions. Healthcare lags other sectors in adopting technologies. Experts predict that Al will bring loads of benefits in every industry globally, wherein the healthcare industry will be a gamechanger. To achieve the goal of Universal health and to address the disease in the 21 st century, research on $\mathrm{Al}$ and its implementation need to consider at the right time for a healthy, wealthy, and resourceful country.

\section{LIMITATIONS AND FUTURE IMPLICATIONS}

The nature of the study is the bibliometric review, as Sreedharan [28] mentioned original articles investigating Al systems were lacking in clinical studies. The researchers cover the outer surface of the healthcare sector research papers in Al. Future researchers can explore the implementation of Al systems concerning specific domains like cardiology, neurology, etc. Finally, future researchers can focus on identifying the gaps in the implementation phase of the Al systems compared to other countries. Health is the basic need for every human, and to make it available to everyone, in the 21 st century, Al systems will be the Rifle of war.

\section{Reference}

1. Chang, A. C. (2020). Artificial intelligence and COVID19: Present state and future vision. Intelligence-Based Medicine, 3(4), p.100012.

2. Chen, M., \& Decary, M. (2020). Artificial intelligence in healthcare: An essential guide for health leaders. In Healthcare management forum.33(1), p.10-18.
3. Kumar, A., Pujari, P., \& Gupta, N. (2021). Artificial Intelligence: Technology 4.0 as a solution for healthcare workers during COVID-19 pandemic. Acta Universitatis Bohemiae Meridionalis, 24(1), p.23-42.

4. Warwick K (2012). Artificial Intelligence: The Basics. Abingdon: Routledge.

5. Buchanan, B. G. (2005). A very brief history of artificial intelligence. Al Magazine, 26(4), p.53-53.

6. Bar-llan, J. (2008b). Which h-index? A comparison of WoS, Scopus and Google Scholar. Scientometrics, 74 (2), p.257-27.

7. Merigo, J. M., Blanco-Mesa, F., Gil-Lafuente, A. M., \& Yager, R. R. (2017). Thirty years of the International Journal of Intelligent Systems: A bibliometric review. International Journal of Intelligent Systems, 32(5), p.526-554.

8. Chang, Y. W., \& Huang, M. H. (2012). A study of the evolution of interdisciplinarity in library and information science: Using three bibliometric methods. Journal of the American Society for Information Science and Technology, 63(1), p.22-33.

9. Van Eck, N.J., \& Waltman, L. (2010). Software survey: VOS viewer, a computer program for bibliometric mapping. Scientometrics, 84(2), p.523-538.

10. Randhawa, G. K., \& Jackson, M. (2020). The role of artificial intelligence in learning and professional development for healthcare professionals. In Healthcare management forum.33(1), p.19-24.

11. Tran, B. X., Vu, G. T., Ha, G. H., Vuong, Q. H., Ho, M. T., Vuong, T. T., \& Ho, R. (2019). Global evolution of research in artificial intelligence in health and medicine: A bibliometric study. Journal of clinical medicine, 8(3), p.360.

12. He J, Baxter SL, XU J, XU J, Zhou X, Zhang K (2019). The practical implementation of artificial intelligence technologies in medicine. Nat Med, 25(1), p.30

13. Amann, J., Blasimme, A., Vayena, E., Frey, D., \& Madai, V. I. (2020). Explainability for artificial intelligence in healthcare: a multidisciplinary perspective. BMC Medical Informatics and Decision Making, 20(1), p.1-9.

14. Kumar, A., \& Ayedee, D. (2021). Technology adoption: A solution for SMEs to overcome problems during COVID-19. Forthcoming, Academy of Marketing Studies Journal, 25(1), p.1-16.

15. lliashenko, O., Bikkulova, Z., \& Dubgorn, A. (2019). Opportunities and challenges of artificial intelligence 
in healthcare. In E3S Web of Conferences, EDP Sciences., 110, p. 02028.

16. Schonberger, D. (2019). Artificial intelligence in healthcare: a critical analysis of the legal and ethical implications. International Journal of Law and Information Technology, 27(2), p.171-203.

17. Arora, A. (2020). Conceptualising artificial intelligence as a digital healthcare innovation: an introductory review. Medical Devices, 13, p.223.

18. Kassam, A., \& Kassam, N. (2020, January). Artificial intelligence in healthcare: A Canadian context. In Healthcare management forum 33(1), p.5-9.

19. Laï, M. C., Brian, M., \& Mamzer, M. F. (2020). Perceptions of artificial intelligence in healthcare: findings from a qualitative survey study among actors in France. Journal of translational medicine, 18(1), p.113.

20. Amann, J., Blasimme, A., Vayena, E., Frey, D., \& Madai, V. I. (2020). Explainability for artificial intelligence in healthcare: a multidisciplinary perspective. BMC Medical Informatics and Decision Making, 20(1), p.1-9.

21. Alugubelli, R. (2016). Exploratory Study of Artificial Intelligence in Healthcare. International Journal of Innovations in Engineering Research and Technology, 3(1), p.1-10.

\section{REFERENCES}

22. Reddy, S., Fox, J., \& Purohit, M. P. (2019). Artificial intelligence-enabled healthcare delivery. Journal of the Royal Society of Medicine, 112(1), p.22-28.

23. Rong, G., Mendez, A., Assi, E. B., Zhao, B., \& Sawan, M. (2020). Artificial intelligence in healthcare: review and prediction case studies. Engineering, 6(3), p.291-301.

24. Davenport, T., \& Kalakota, R. (2019). The potential for artificial intelligence in healthcare. Future healthcare journal, 6(2), p.94.

25. Yu, K. H., Beam, A. L., \& Kohane, I. S. (2018). Artificial intelligence in healthcare. Nature biomedical engineering, 2(10), p.719-731.

26. Jiang, F., Jiang, Y., Zhi, H., Dong, Y., Li, H., Ma, S., \& Wang, $Y$. (2017). Artificial intelligence in healthcare: past, present and future. Stroke and vascular neurology, 2(4), p.230-243.

27. Bakshi, G., Kumar, A., \& Puranik, A. N. (2022). Adoption of Robotics Technology in Healthcare Sector. In Advances in Communication, Devices and Networking, 776, p. 405-414.

28. Sreedharan, S., Mian, M., Robertson, R. A., \& Yang, N. (2020). The top 100 most cited articles in medical artificial intelligence: A bibliometric analysis. Journal of Medical Artificial Intelligence, 3, p.1-12. 